\title{
Lesões necróticas na disjunção palatina: explicação e prevenção
}

\section{O suprimento sanguíneo do palato deve ser considerado no planejamento}

\author{
Alberto Consolaro*, Valdomiro Rebellato Júnior**, Maria Fernanda M-O. Consolaro***,

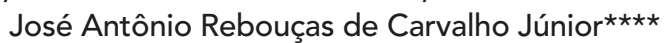

A anatomia do palato, em especial a vasculatura responsável pelo seu aporte sanguíneo, deve ser mais um dos fatores considerados no planejamento da disjunção palatina, especialmente na confecção do aparelho. Essa disjunção está indicada para aumentar as medidas transversais da face. Esse aumento é obtido às custas da separação das maxilas, com posterior ossificação do espaço conseguido na sutura palatina mediana. Esse procedimento é realizado entre os 10 e os 15 anos de idade, mas na idade adulta também pode-se conseguir resultados satisfatórios. $\mathrm{O}$ aparelho disjuntor das maxilas mais utilizado, desde $1961^{8}$, é o disjuntor tipo Haas ${ }^{5-9}$. A eficiência dos aparelhos disjuntores palatinos dentomucossuportados vai depender da frequência, intensidade e duração da força da estrutura acrílica sobre o palato e da estrutura metálica sobre os dentes.

A força aplicada pelos aparelhos dentomucossuportados pode, eventualmente, provocar isquemia na região, por compressão das artérias palatinas, promovendo redução do fluxo sanguíneo na mucosa e submucosa do palato ou até, em casos extremos, o infarto das glândulas salivares menores, com ulceração (Fig. 1, 2).

\section{Consequências da isquemia no palato e o conceito de "Sialometaplasia Necrosante"}

A necrose isquêmica caracteriza a alteração conhecida como infarto, um termo muito conhecido e aplicado no miocárdio, mas que pode ocorrer em várias partes do corpo. O infarto, ou a necrose isquêmica, pode ocorrer no palato e afetar especialmente as glândulas salivares, pelo fato de suas células acinares - aquelas que produzem a saliva - apresentarem um alto grau de diferenciação e serem muito sensíveis à falta de oxigênio. Em estado de hipóxia, as células acinares podem necrosar, mas as células dos ductos glandulares e as células mioepiteliais ${ }^{14}$ resistem e persistem, podendo até modificar o seu fenótipo de células ductais para células de epitélio estratificado pavimentoso ou escamoso, assim chamado pela sua propriedade de esfoliar-se como escamas quando reveste uma superfície corporal. Mudanças de fenótipos em células e tecidos maduros recebem o nome de metaplasia e, nesse caso, são identificadas como metaplasia escamosa.

Quando o infarto isquêmico ocorre, o tecido necrosado tem que ser removido, eliminado ou excretado de alguma forma pelo organismo. A forma

* Professor Titular da FOB-USP e da Pós-graduação da FORP-USP.

** Mestre em Patologia Bucal pela FOB-USP.

*** Professora Doutora de Ortodontia e Biologia Oral da USC-Bauru.

**** Mestre e Doutor em Cirurgia Bucomaxilofacial pela UNESP-Araçatuba. 


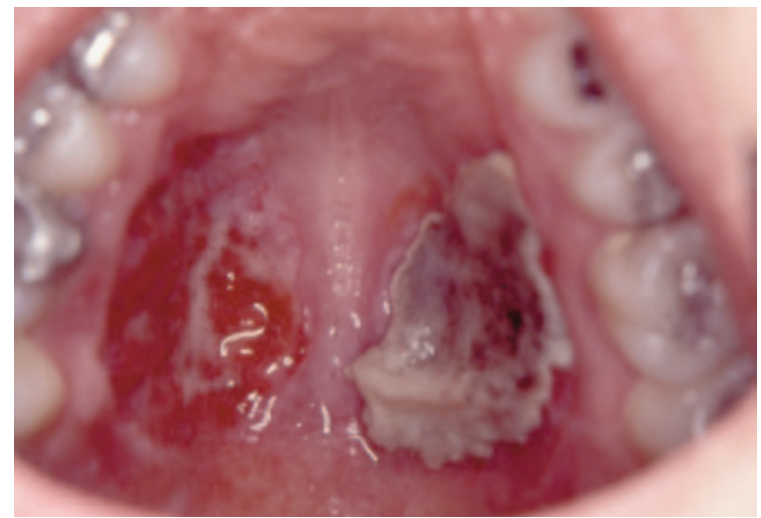

FIGURA 1 - Duas ulcerações na mucosa palatina correspondentes às áreas de compressão da parte acrílica do aparelho disjuntor palatino. A ferida da direita encontra-se recoberta por uma pseudomembrana de tecido mucoso necrosado esbranquicado. Na ferida da esquerda, a mucosa necrosada foi eliminada naturalmente e apresenta leito avermelhado e sangrante ao toque.

encontrada, no caso dos infartos anêmicos das glândulas salivares menores do palato, para se eliminar o tecido necrosado é sua aproximação e decorrente necrose do epitélio da mucosa palatina e consequente ulceração. Uma ferida se abre no palato (Fig. 1, 2) e, após a eliminação do tecido necrosado pela ulceração, em algumas semanas, evolui-se para a reparação (Fig. 3) com marcas discretas na mucosa palatina, muitas vezes clinicamente imperceptiveis.

A designação de doenças ou palavras relacionadas com as glândulas salivares utiliza-se dos sufixos "sialo" (do grego síalon = saliva). Quando ocorre o processo de infarto anêmico das glândulas salivares menores do palato, há necrose das células acinares e a metaplasia escamosa das células epiteliais ductais e mioepiteliais. Por isso, esse estado clínico ou doença passou a ser denominado Sialometaplasia Necrosante ou Necrotizante.

Eventualmente, a mucosa e a submucosa bucais podem também ser induzidas a uma necrose isquêmica por uma ação física direta do acrílico, sem o envolvimento das glândulas salivares menores (Fig. 1).

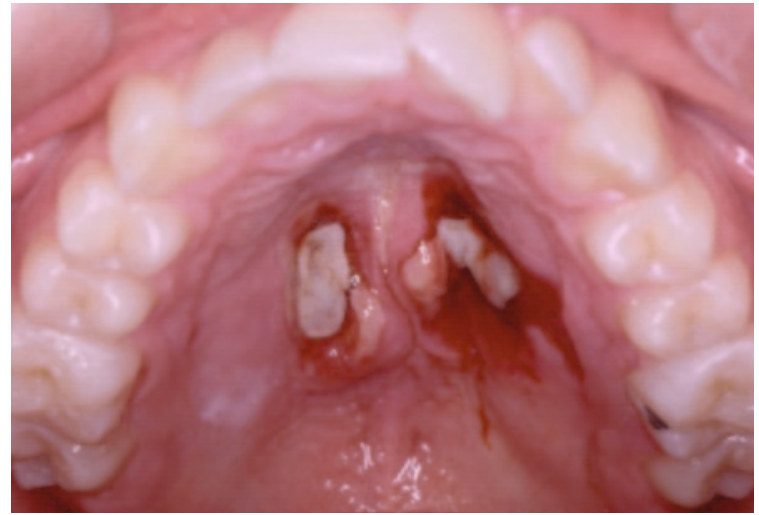

FIGURA 2 - As ulcerações correspondentes às áreas de contato da parte acrílica com a mucosa palatina apresentaram o tecido necrosado esbranquiçado e em desprendimento do leito sanguinolento, logo após a retirada do aparelho disjuntor palatino. Esse tecido foi removido delicadamente com instrumentos, pois atrasa o reparo e pode ser sede de microrganismos, promover odor fétido e não tem sensibilidade. Prescreveu-se, em seguida, antisséptico não-alcoólico, analgésico e antibioticoterapia de largo espectro.

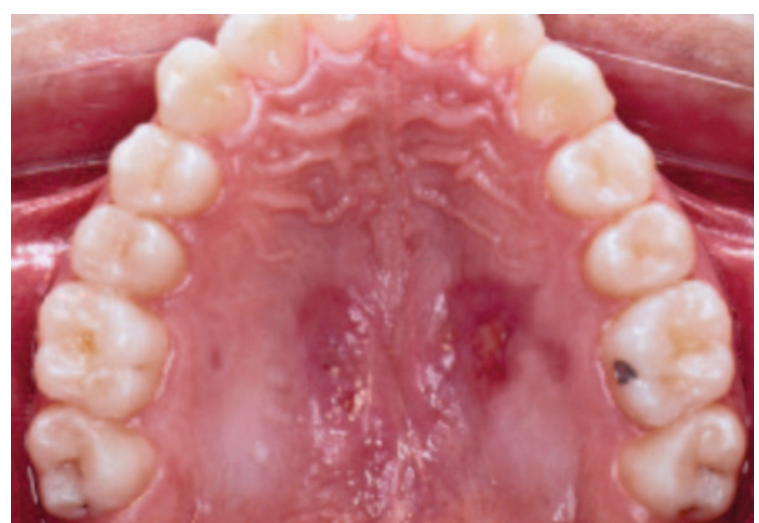

FIGURA 3 - Após 7 dias do tratamento, as ulcerações mostradas na figura 2 apresentaram-se em regressão, com a maior parte do leito cirúrgico recoberto por mucosa em regeneração. A exposição do tecido conjuntivo limita-se a uma pequena área central.

\section{Quando e por que ocorre a Sialometaplasia Necrosante}

Os sinais e sintomas clínicos desse infarto anêmico das glândulas salivares palatinas, ou Sialometaplasia Necrosante, podem aparecer em decorrência de traumatismos locais após a ingestão de alimentos duros como os churrascos, traumatismos físicos acidentais na mucosa bucal, após injeções anestésicas e outras causas que possam comprimir 
as artérias responsáveis pelo suprimento sanguíneo de uma determinada área. $\mathrm{Na}$ anamnese desses casos, geralmente consegue-se recuperar algum fato que justifique essa necrose local. A Sialometaplasia Necrosante não é exclusiva do palato duro e pode ocorrer também em outras partes da mucosa bucal, como na língua, lábios e soalho bucal.

O aspecto clínico da ulceração promovida pela Sialometaplasia Necrosante representa uma lesão inflamatória benigna, mas é comumente confundida e diagnosticada clinicamente, e até microscopicamente, como Carcinoma Mucoepidermoide e Carcinoma Espinocelular 1,2,4,10,12,13. Microscopicamente, o patologista também pode confundirse e o diagnóstico desse tipo de carcinomas pode ser estabelecido em laudos histopatológicos ${ }^{1,2}$. A Sialometaplasia Necrosante representa uma lesão autolimitante pela autorresolução, sem maiores consequências quando comparadas às promovidas pelo Carcinoma Espinocelular e Mucoepidermoide e/ou pelas sequelas de seus tratamentos.

Os sinais e sintomas são dor, febre, ardência e parestesia, os quais não acontecem simultaneamente em todos os casos. A reparação (Fig. 3) ocorre em aproximadamente cinco semanas ${ }^{2,4,10}$. Pode-se prescrever analgésicos, anti-inflamatórios e antibioticoterapia para a prevenção de infecções oportunistas.

\section{A disjunção palatina e a Sialometaplasia Necrosante}

A ulceração na mucosa palatina observada durante as disjunções ocorre eventualmente na clínica ortodôntica e pode ser considerada iatrogênica, mas não tem esse caráter na maioria dos casos. A parte acrílica dos disjuntores dentomucossuportados pode comprimir as artérias palatinas e induzir a Sialometaplasia Necrosante no palato duro. $\mathrm{Na}$ prática clínica ortodôntica, quando ulcerações ocorrem na disjunção palatina, as seguintes causas podem ser atribuídas:

1. ossificação da sutura e impedimento de sua abertura, concentrando as forças aplicadas sobre a mucosa e os dentes. Quando isso ocorre, o paciente geralmente demorou excessivamente para procurar a orientação do profissional, mesmo com sintomatologia muito dolorosa.

2. ativação inadequada, por parte do paciente, durante a aplicação das voltas no parafuso do aparelho;

3. quebra do aparelho e ação indevida do acrílico sobre a mucosa palatina;

4. ancoragem dentária inadequada ou insuficiente, ineficiente na transmissão das forças do parafuso expansor, gerando vestibularização dentária e consequente sobrecarga no palato.

Esse tipo de intercorrência durante a disjunção palatina pode ser muito mais comum do que é relatado, pois em geral assusta muito o profissional e o paciente, promovendo uma sensação de erro, negligência e, em consequência, iatrogenia - quando em muitos casos foram consequências de quebras dos aparelhos, confecção inapropriada da parte acrílica ou resultado de uma variação anatômica do palato. O conhecimento sobre a importância do tipo de palato e do trajeto das artérias palatinas no planejamento da disjunção palatina com aparethos dentomucossuportados poderia evitar muitos casos de ulcerações no palato (Fig. 4 - 10).

\section{A vasculatura do palato duro a ser considerada na disjunção palatina}

O conhecimento prévio da vasculatura e suprimento sanguíneo do palato duro levará ao planejamento mais adequado da área de contato da parte acrílica do aparelho com a mucosa.

O palato é irrigado anteriormente pela artéria esfenopalatina e posteriormente pelas artérias palatinas maior e menor ${ }^{3,11}$ (Fig. 4). Na altura do canino, essas artérias podem anastomosar ${ }^{3} . \mathrm{Na}$ submucosa palatina há muitas glândulas salivares menores, especialmente na sua metade mais posterior ${ }^{18}$. Na metade anterior do palato, o tecido conjuntivo da submucosa é bem fibroso e muito fino. Logo abaixo do epitélio, entre as suas cristas, temos as papilas conjuntivas, mas imediatamente 


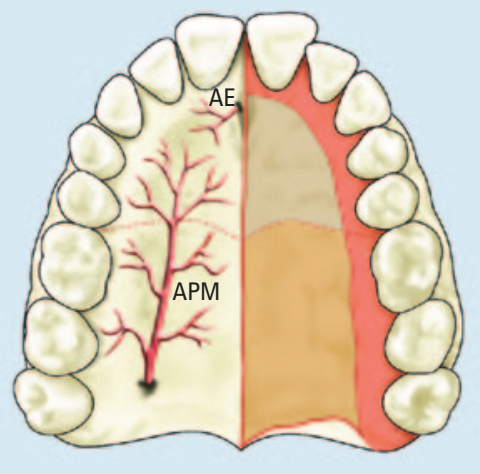

FIGURA 4 - Diagrama demonstrativo da vascularização do palato: artéria palatina maior (APM) e artéria esfenopalatina (AE).

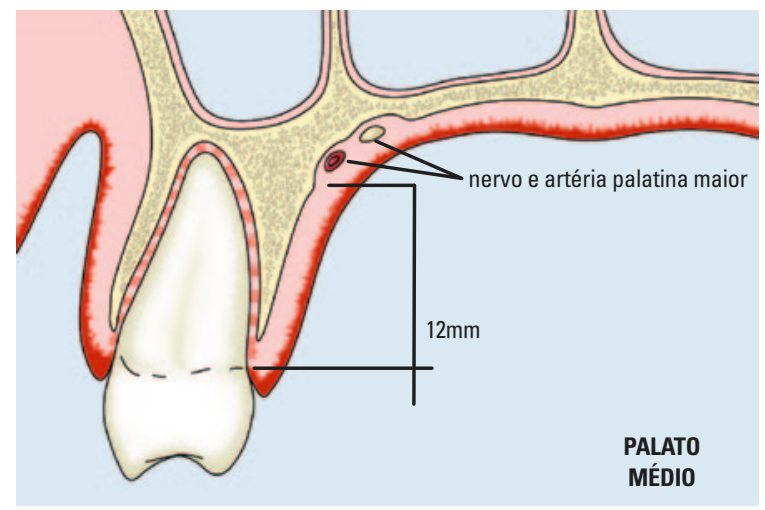

FIGURA 6 - Palato médio: caracterizado pela distância média de $12 \mathrm{~mm}$ entre a junção amelocementária e a artéria palatina maior, de acordo com critério de Reiser et al. ${ }^{17}$

abaixo se encontra uma submucosa fina e fibrosa que se une diretamente ao periósteo. O periósteo representa a principal fonte sanguínea para o osso.

$\mathrm{Na}$ parte anterior, a artéria esfenopalatina emerge do forame incisivo, cuja localização pode ser clinicamente reconhecida a partir da papila incisiva. Na parte posterior do palato, emerge a artéria palatina maior do forame palatino maior (Fig. $4,8)$. Esse forame localiza-se, aproximadamente, entre os segundo e terceiro molares, na altura do ângulo formado pela parte vertical e horizontal do

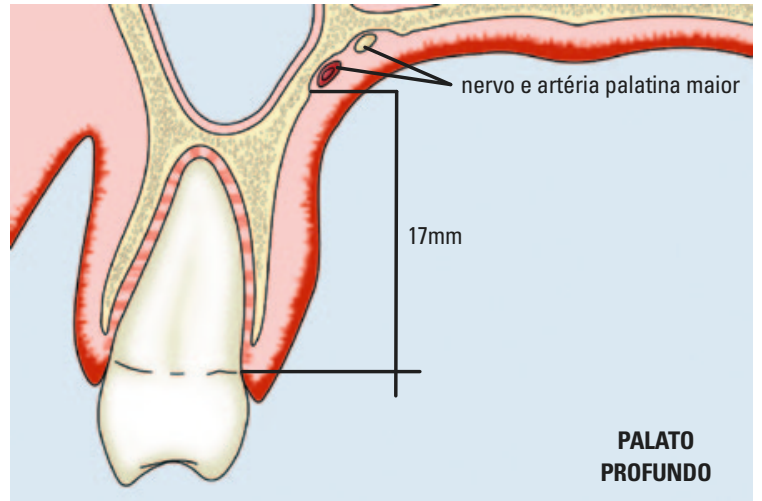

FIGURA 5 - Palato profundo: caracterizado pela forma de abóbada alta ou de "U" e com 17mm em média entre a junção amelocementária e a artéria palatina maior, de acordo com critério de Reiser et al. ${ }^{17}$

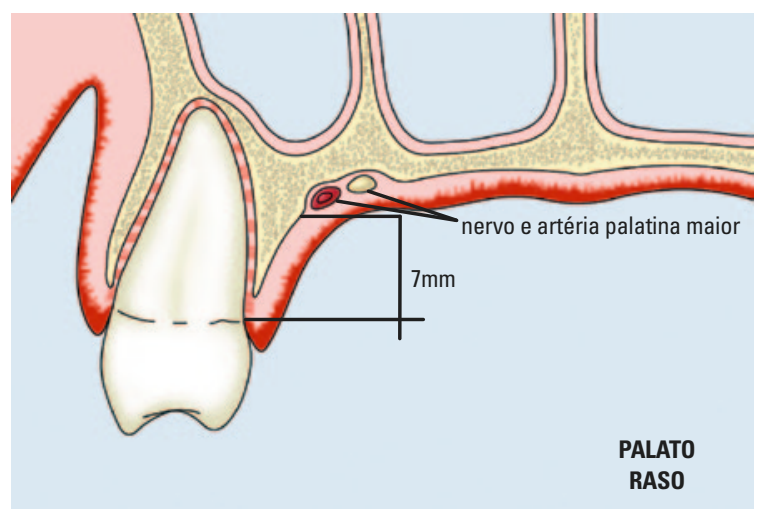

FIGURA 7 - Palato raso: caracterizado pela distância média de $7 \mathrm{~mm}$ entre a junção amelocementária e a artéria palatina maior, de acordo com critério de Reiser et al. ${ }^{17}$

palato duro. Logo na sua saída há um sulco por onde ela percorre em direção anterior. Muitas vezes, nas margens desse sulco formam-se verdadeiras cristas ósseas (Fig. 5, 6, 7). Esse local de emergência da artéria palatina maior pode ser percebido à palpação. Nessa região tem-se, ainda, a irrigação sanguínea secundária por parte da artéria palatina menor, que emerge dos forames palatinos, menores e bem posteriormente localizados.

As duas principais artérias do palato duro são do tipo terminal ou arboriforme. Apesar de 
eventuais anastomoses na altura dos caninos, se alguma redução do fluxo acontecer em uma das artérias, a isquemia provocada não será devidamente compensada por outros vasos e pode levar a região isquêmica à necrose, estabelecendo-se clinicamente como lesões ulceradas.

\section{A prevenção e o tratamento da Sialometaplasia Necrosante na disjunção palatina}

$\mathrm{Na}$ disjunção palatina, há tempo e força suficientes para o acrílico do aparelho comprimir a artéria palatina maior, o principal vaso sanguíneo do palato duro, provocando isquemia e necrose da submucosa palatina e resultando no infarto das glândulas salivares menores ou Sialometaplasia Necrosante com ulceração no palato duro.

Os aparelhos disjuntores palatinos, em quase sua totalidade, são confeccionados independentemente das particularidades da vascularização palatina e, até o estudo de Rebellato Júnior ${ }^{15}$ em 2003, nenhum protocolo de manufatura havia sido desenvolvido visando evitar a ocorrência dessas lesões. A Sialometaplasia Necrosante no palato foi relatada pela primeira vez em 1973 por Abrams, Melrose e Howell ${ }^{1}$, mas nunca foi relacionada ao uso de aparelhos disjuntores palatinos. A compressão da mucosa bucal pode lesar internamente os vasos e provocar a sua obstrução total ${ }^{7}$. Os componentes teciduais mais sensíveis à hipóxia podem necrosar rapidamente. A inflamação periférica tenderá a expulsar os tecidos necrosados, promovendo uma ulceração ${ }^{4}$.

A fina e fibrosa submucosa palatina apresenta uma estrutura delicada e facilmente comprimível à pressão por parte do acrílico do aparelho disjuntor na região mais anterior do palato (Fig. 1). Embora não tenha sido descrito antes de Rebellato Júnior ${ }^{15}$, na região posterior, pelo grande número de glândulas salivares, a compressão e isquemia prolongada por aparelhos disjuntores palatinos pode resultar em Sialometaplasia Necrosante, uma lesão de natureza inflamatória e benigna, pois, quando removida a causa, tende ao reparo com ou sem cicatrizes, dependendo da extensão da lesão $0^{2,4}$.

No planejamento do aparelho, quando se delineia a extensão do acrílico (Fig. 9, 10), deveria ser levada em consideração a anatomia palatina, em especial a sua vasculatura. Ao aliviar a região por onde passa a artéria palatina maior, pode-se evitar sua compressão e a possibilidade de ocorrer ulceração necrótica.

Em 1996, Reiser et al. ${ }^{17}$ estudaram a localização da artéria palatina maior, pois estavam preocupados com a escolha de áreas doadoras de mucosa para enxertos gengivais. A partir dos pré-molares e molares, entre a junção esmalte-cemento e o sulco ósseo palatino por onde passa a artéria palatina maior, consideraram a distância variável de 7 a $17 \mathrm{~mm}$, de acordo com o grau de profundidade do palato, apesar de seus dados estarem embasados em comunicação pessoal. Eles estabeleceram os seguintes parâmetros:

a) Quando o palato tiver a abóbada alta ou em forma de "U", a artéria estaria, em média, a $17 \mathrm{~mm}$ da junção amelocementária (Fig. 5).

b) Nos casos médios, a artéria estaria em média a $12 \mathrm{~mm}$ da junção amelocementária (Fig. 6).

c) Quando o palato for raso, a distância seria, em média, de $7 \mathrm{~mm}$ (Fig. 7).

Para Redman, Shapiro e Gorlin ${ }^{16}$, a altura do palato - correspondente à distância entre a junção amelocementária e a parte mais alta do palato, onde se localiza a artéria palatina maior - em adolescentes do gênero masculino é de 14,90 \pm 2,93mm em média, e nos do gênero feminino é de $12,70 \pm 2,45 \mathrm{~mm}$. Reiser et al. ${ }^{17}$ sugerem a palpação como método clínico de localização da artéria palatina maior, e sua demarcação com caneta para a escolha da área doadora dos enxertos gengivais (Fig. 9). A artéria palatina maior emerge do forame palatino maior, percorre em direção anterior do palato, paralela aos dentes posteriores e, na altura dos caninos, angula-se em sua direção (Fig. 8).

Para evitar a ocorrência das ulcerações decorrentes da Sialometaplasia Necrosante durante a 


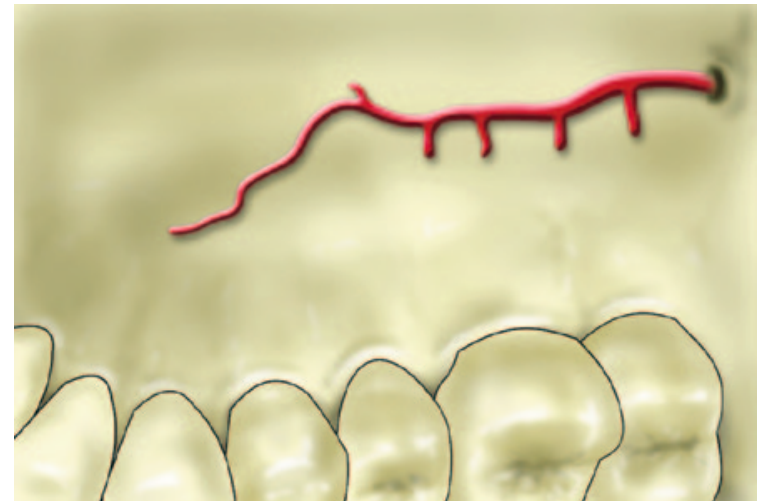

FIGURA 8 - A artéria palatina maior emerge do forame palatino maior e prolonga-se para a porção anterior do palato, paralelamente aos dentes posteriores, angulando-se em direção ao canino.

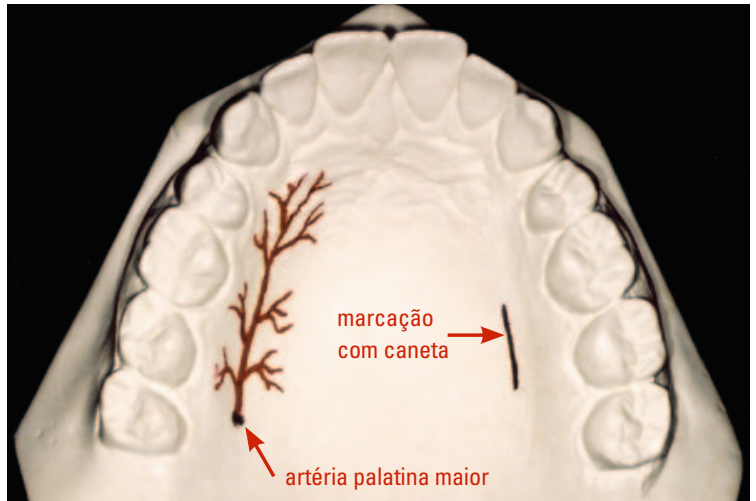

FIGURA 9 - Localização da artéria palatina maior, delineada no modelo de gesso onde o acrílico do disjuntor palatino será posicionado. As marcações com caneta podem ser realizadas nos modelos para orientar 0 protético a confeccionar alívios no local de inserção do acrílico e, com isso, evitar a compressão nas áreas sensíveis.

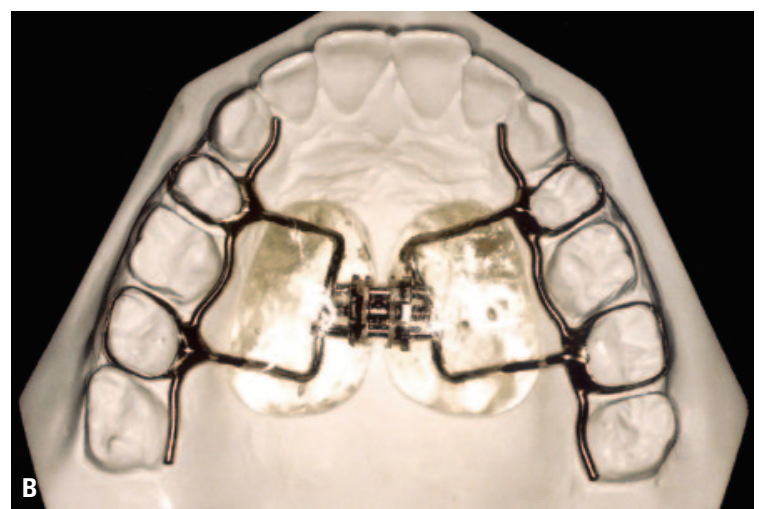

FIGURA 10 - No planejamento para a confecção do aparelho disjuntor palatino, nota-se que a área de contato da parte acrílica pode ser delimitada (em A) para que os alívios nas áreas do trajeto da artéria palatina maior sejam providenciados. Dessa forma, a artéria palatina maior não será comprimida pelo acrílico (em B) e a ocorrência de necrose isquêmica será evitada, prevenindo-se a Sialometaplasia Necrosante.

disjunção palatina, sugerimos levar em consideração as características morfológicas do palato, como sua forma e profundidade. Na palpação digital do palato na região dos molares, pode-se detectar o sulco palatino na superfície óssea por onde passa a artéria palatina maior. A demarcação bilateral com tinta do local da artéria palatina maior, no modelo sobre o qual será delineada a área de apoio mucoso do acrílico, permitirá a realização de alívios ou contornos, evitando-se sua compressão (Fig. 9, 10).

Nos casos de ulceração induzida pelos disjuntores palatinos, em geral não há necessidade de biópsia, pela evidente relação causa-efeito estabelecida, mas caso exista alguma dúvida diagnóstica ela deve ser realizada. Como é decorrente da ação física do aparelho, a ulceração deve ser limpa com antissépticos não-alcoólicos para eliminação dos restos necróticos e alimentares. As soluções anestésicas podem ser indicadas para alívio do desconforto durante a alimentação. Analgésicos podem ser administrados em caso de dor ou desconforto maior. A antibioticoterapia de largo espectro previne infecções oportunistas e deve durar até o fechamento completo da lesão (Fig. 2, 3). 


\section{Consideração final}

$\mathrm{Na}$ disjunção maxilar, a anatomia do palato, em especial a vasculatura responsável pelo seu aporte sanguíneo, deve ser mais um dos fatores a ser considerado. A compressão das artérias palatinas pode ocorrer durante a disjunção maxilar e promover a necrose tecidual da submucosa palatina, inclusive das glândulas salivares menores, promovendo uma ulceração da área. Isso pode ser evitado apontando-se, com marcações nos modelos, a localização da artéria palatina maior, indicando, assim, durante a confecção de aparelhos disjuntores dentomucossuportados, os locais de alívios e contornos adequados da sua parte acrílica.

\section{REFERÊNCIAS}

1. ABRAMS, A. M.; MELROSE, R. J.; HOWELL, F. V. Necrotizing sialometaplasia: A disease simulating malignancy. Cancer, Hoboken, v. 32, no. 1, p. 130-135, Jul. 1973.

2. ANNEROT, H. G.; HANSEN, L. S. Necrotizing sialometaplasia: The relationship of its pathogenesis to its clinical characteristics. Int. J. Oral Surg., Copenhagen, v. 11, no. 5, p. 283-291, Oct. 1982.

3. DELLA SERRA, O.; FERREIRA, F. V. Anatomia dental. 3. ed. São Paulo: Artes Médicas, 1981.

4. GAHHOS, F.; ENRIQUEZ, R. E.; BAHN, S. L.; ARIYAN, S. Necrotizing sialometaplasia: Report of five cases. Plast. Reconstr. Surg., Hagerstown, v. 71, p. 650-657, 1983.

5. HAAS, A. J. Interviews. J. Clin. Orthod., Boulder, v. 7 , p. 227-245, 1973.

6. HAAS, A. J. Long-term posttreatment evaluation of rapid palatal expansion. Angle Orthod., Appleton, v. 50, no. 3 , p. 189-217, July 1980 .

7. HAAS, A. J. Palatal expansion: Just the beginning of dentofacial orthopedics. Am. J. Orthod., St. Louis, v. 57, no. 3, p. 219-255, Mar. 1970.

8. HAAS, A. J. Rapid expansion of the maxillary dental arch and nasal cavity by opening the midpalatal suture. Angle Orthod. Appleton, v. 31, no. 2, p. 73-90, Apr. 1961

9. HAAS, A. J. The treatment of maxillary deficiency by opening the midpalatal suture. Angle Orthod., Appleton, v. 35, no. 3, p. 200-217, 1965.

10. LAMEY, P. J.; LEWIS, M. A. O.; CRAWFORD, D. J.; MAcDONALD, D. G. Necrotising sialometaplasia presenting as greater palatine nerve anaesthesia. Int. J. Oral Maxillofac. Surg., Copenhagen, v. 18, no. 2, p. 70-72, Apr. 1989.
11. LINDHE, J. Tratado de Periodontia Clínica e Implantologia oral. 3. ed. Rio de Janeiro: Guanabara Koogan, 1999

12. MURPHY, J.; GIUNTA, J.; MEYER, I.; ROBINSON, K. Necrotizing sialometaplasia. J. Oral Surg., Chicago, v. 44, no. 3, p. 419-424, 1977.

13. NILSEN, R.; BERNHOFT, C. H.; GILHUUS-MOE, O. Necrotizing sialometaplasia. Int. J. Oral Surg., Copenhagen, v. 7, no. 6, p. 580-584, 1978.

14. ORBAN, B. J. Histologia e Embriologia Oral de Orban 10. ed. São Paulo: Artes Médicas, 1989.

15. REBELLATO JÚNIOR, V. Análise microscópica da sialometaplasia necrosante e apresentação de uma hipótese sobre suas relações etiopatogênicas, em especial com aparelhos disjuntores palatinos. 2003. Dissertação (Mestrado)-Faculdade de Odontologia de Bauru, Universidade de São Paulo, Bauru, 2003.

16. REDMAN, R. S.; SHAPIRO, B. L.; GORLIN, R. J. Measurement of normal and reportedly malformed palatal vaults. II. Norma juvenile measurements. J. Dent. Res., Alexandria, v. 45, no. 2, p. 266-269, Mar./Apr. 1966.

17. REISER, G. M.; BRUNO, J. F.; MAHAN, P. E.; LARKIN, L. H. The subepithelial connective tissue graft palatal donor site: Anatomic considerations for surgeons. Int. J. Periodontics Restorative Dent., Chicago, v. 16, no. 2, p. 130-137, Apr. 1996.

18. SICHER, H.; DUBRUL, E. L. Anatomia oral. 8. ed. São Paulo: Artes Médicas, 1991.
Endereço para correspondência

Alberto Consolaro

E-mail: consolaro@uol.com.br 